\title{
Distribuição espacial dos homicídios na cidade de Belém (PA): entre a pobreza/ vulnerabilidade social e o tráfico de drogas
}

\author{
Homicide growth in the city Belem (Brazil): between poverty/ \\ social vulnerability and drug trafficking
}

Rosália do Socorro da Silva Corrêa iD, Marco Aurélio Arbage Lobo iD

Universidade da Amazônia (UNAMA), Programa de Mestrado e Doutorado em Desenvolvimento e Meio Ambiente Urbano, Belém, PA, Brasil

Como citar: Corrêa, R. S. S., \& Lobo, M. A. A. (2019). Distribuição espacial dos homicídios na cidade de Belém (PA): entre a pobreza/vulnerabilidade social e o tráfico de drogas. urbe. Revista Brasileira de Gestão Urbana, v. 11, e20180126. https://doi.org/10.1590/2175-3369.011.e20180126

\section{Resumo}

A relação entre pobreza/vulnerabilidade social e a violência urbana tem sido objeto de inúmeros estudos no Brasil. Contudo, ocorreu um fenômeno aparentemente contraditório para essa explicação: houve melhoria de vários indicadores sociais no período 2000-2010, mas a incidência de homicídios, indicador fundamental da criminalidade violenta, aumentou. Diante disso, é válido supor que, além da pobreza/vulnerabilidade social, outros fatores interferem na ocorrência de homicídios. Este estudo sugere a hipótese de que o tráfico de drogas é um desses fatores. Para isso, realizou-se um estudo de caso sobre a cidade de Belém (PA), que inicia pela investigação da distribuição geográfica das taxas médias de homicídios no período 2013-2015 nos bairros localizados na área continental da cidade. Em seguida, há uma análise estatística dos mesmos dados, baseada na comparação entre dois modelos de regressão linear, um somente com variáveis relacionadas à pobreza/vulnerabilidade social; e outro que, além dessas variáveis, inclui o número de ocorrências de tráfico de drogas. Os resultados mostraram que o segundo modelo apresentou maior poder explicativo do que o primeiro. Isso corrobora a hipótese de que o tráfico de drogas contribui para o aumento da incidência de homicídios.

Palavras-chave: Homicídios. Pobreza/vulnerabilidade social. Tráfico de drogas.

\section{Abstract}

The relationship between poverty/social vulnerability and urban violence has been subject of numerous studies in Brazil. However, a seemingly contradictory phenomenon occurred for this explanation: there was an improvement in several social indicators in the period 2000-2010, but the incidence of homicides, a key indicator of violent crime, has increased. Given this, it is valid to suppose that, in addition to poverty/social vulnerability, other factors interfere in the occurrence of homicides. This study suggests the hypothesis that drug trafficking is one such factor. To do this, it carries out a case study on the city of Belem (Brazil), which begins by the investigation of the geographical distribution of the average homicide rates for the period 
2013-2015 in the neighborhoods located in the continental area of the city. It then develops a statistical analysis of the same data based on the comparison of two linear regression models, one with only variables related to poverty/social vulnerability; and another that, besides these variables, adds the number of drug trafficking occurrences. The results showed that the second model had better explanatory power than the first one. This corroborates the hypothesis that drug trafficking is a contributing factor to the increased incidence of homicides.

Keywords: Homicide. Poverty/Social Vulnerability. Drug Trafficking.

\section{Introdução}

A associação entre as situações de pobreza/vulnerabilidade ${ }^{1}$ social e a violência urbana está comumente no imaginário social e foi objeto de inúmeros estudos no Brasil, em especial na década de 80 (Misse, 1993; 1995). Sem discordar dessa assertiva, observa-se que ocorreu um fenômeno aparentemente contraditório para essa explicação: houve melhoria de vários indicadores sociais no período 2000-2010, mas a ocorrência de homicídios - indicador fundamental da criminalidade violenta - aumentou.

Um exemplo desse fenômeno é o município de Belém (PA), situado na Região Norte, com população estimada em 1.452.275 (IBGE, 2017). Ainda segundo o IBGE, entre 2000 e 2010, o índice de Gini da renda média domiciliar per capita caiu de 0,6460 para 0,6284, o que indica uma ligeira queda no grau de concentração de renda; a taxa de analfabetismo na população de 15 anos ou mais de idade reduziu de 13,6\% para 9,6\%; o percentual de pessoas desocupadas, em relação ao total da população economicamente ativa de 10 anos e mais na semana de referência do Censo Demográfico, reduziu de 10,2\% para 5,7\%; e a renda média domiciliar per capita incrementou de $\mathrm{R} \$ 618$ (valor corrigido pelo IPC-A/IBGE) para R\$ 855, o que significou um aumento real de $38,3 \%$.

Com base nesses números, seria esperada uma redução na criminalidade violenta, mas o que aconteceu foi justamente o contrário: nesse mesmo período, o coeficiente de homicídios por 100 mil habitantes na capital paraense subiu de 25,9 para 54,4, ou seja, 110,4\% (Waiselfisz, 2011a).

Dessa forma, é válido supor que, além da pobreza, que propicia a vulnerabilidade social, outros fatores interferem na ocorrência de homicídios e outras formas de criminalidade violenta. Este estudo apresenta a hipótese de que o tráfico de drogas é um desses fatores.

A partir desse cenário, discute-se uma provável relação entre os homicídios e o tráfico de drogas, em área urbana, um vínculo que se supõe estar assentado numa racionalidade de mercado, quando visa manter a capacidade produtiva e o atendimento à demanda consumidora de drogas, eliminando qualquer obstáculo à garantia desse movimento comercial. Nessa direção é oportuno prever que as situações de rivalidades oriundas das disputas por território entre traficantes; do desrespeito à hierarquia imposta às relações e aos códigos normativos que orientam a comercialização da droga; e da dificuldade de pagar dívidas de consumo ou revenda do produto, podem custar a vida, notadamente daqueles que operam nas pontas da rede do tráfico.

Esse raciocínio conduz à hipótese de que na cidade de Belém, capital do estado do Pará, localizada na Região Norte do Brasil, a distribuição espacial dos homicídios por bairros, observados entre os anos 2013 a 2015 está relacionada não somente à pobreza/vulnerabilidade social, como também ao crescimento do tráfico de drogas, constatado nesse mesmo período. Essa hipótese tem se mostrado pouco acessível à

\footnotetext{
1 Admitimos e apoiamos as discussões sobre a abrangência e complexidade do conceito de pobreza (Sen, 2008); Schwartzman, 2004; Reis e Schwartzman, 2004), as quais defendem que este conceito não se reduz à insuficiência da renda, mas alcança uma diversidade de carências que conduzem à vulnerabilidade que, por sua vez, se vincula a diferentes fragilidades incluindo as noções de riscos (possibilidade de pessoas sofrerem perturbações derivadas de diferentes fenômenos e fragilidade quanto às suas capacidades de compreender e enfrentar esses riscos), de perda de bem-estar, de cidadania e de proteção social, mas também está relacionada à desigualdade de acesso aos bens e aos serviços públicos (Santos, 2015). Para evitar equívocos quanto ao uso dos termos pobreza e vulnerabilidade social, decidimos aproximar os termos por entendermos que a pobreza, enquanto estado de carência, torna-se um elemento propulsor da vulnerabilidade social, que se articula à noção de risco e coloca pessoas e grupos diante da ameaça de um porvir, o que nessa discussão se relaciona à criminalidade violenta. Entretanto, para os propósitos deste estudo, limitamos a situação de pobreza/vulnerabilidade social, da área pesquisada, a três variáveis sociais (rendimento médio mensal per capita, população não-branca e domicílios monoparentais com dois ou mais moradores).
} 
comprovação científica, por duas razões mais aparentes: a dificuldade de acesso aos dados sobre o fenômeno do tráfico de drogas no Brasil e a diversidade das motivações que envolvem um homicídio, o que muitas vezes escapa aos registros que servem como fontes das pesquisas, além de outros aspectos que não são considerados nestes casos.

[...] o nível de impunidade existente no Brasil é certamente também um fator para o aumento das taxas de mortalidade entre os pequenos traficantes, visto que esses homicídios não são cuidadosamente examinados. Uma porcentagem incrivelmente elevada de homicídios não é objeto de inquérito policial, e seus autores não são jamais identificados. Um estudo do sistema criminal de Justiça em São Paulo revelou que as maiores porcentagens de condenação estão entre os acusados de tráfico de drogas ou de roubo, e não entre os acusados de homicídios e assalto à mão armada, os dois crimes que mais apavoram as pessoas. Ainda um outro provou que, de 4.277 boletins de ocorrência de homicídios, apenas $4,6 \%$ tiveram o autor e o motivo conhecidos e registrados. No Rio de Janeiro, mais um estudo mostrou que $92 \%$ dos casos de homicídio foram devolvidos à polícia porque não tinham as provas necessárias para serem julgados (Soares et al., 1996) (Zaluar, 2007, p.43-44).

Em relação à criminalidade urbana, observou-se o crescimento dos homicídios em vários estudos (Waiselfisz, 2016a; Cerqueira, 2017; FBSP, 2016; Engel, 2015) e a ampliação, organização e instalação do crime organizado ${ }^{2}$, que tem entre as suas atividades comerciais o tráfico de drogas, um crime que se alastra, cada vez mais nas cidades brasileiras, através da atuação dos grupos ligados a essas organizações que disputam a posse dos territórios para estabelecer pontos de comercialização (Zaluar, 2010).

O objetivo desse estudo foi levantar e analisar elementos que possam relacionar a distribuição espacial dos homicídios por bairros tanto às situações de pobreza/vulnerabilidade social quanto ao tráfico de drogas na cidade de Belém, no período entre 2013 a 2015. Para isso foram realizadas análises geográficas e estatísticas, tomando como variáveis a localização dos bairros onde foram registradas ocorrências de homicídios, no período referido, as condições sociais e econômicas dos moradores desses bairros, a segregação espacial da cidade e a ocorrência de tráfico de drogas.

0 estudo ficou limitado à parte continental do município (área aproximada de $174 \mathrm{~km}^{2}$ ) por motivos estatísticos, como será explicado na próxima seção. Ressalte-se que Belém também possui parte do seu território formado por uma área insular (com cerca de $332 \mathrm{~km}^{2}$ ), composta por 42 ilhas.

0 principal produto da abordagem estatística é um modelo de regressão linear que, além de servir para analisar o fenômeno em questão, poderá ser utilizado para estimar a taxa de homicídios em outras áreas da Região Metropolitana de Belém que não foram consideradas no presente estudo, informação esta que pode ser bastante útil para o planejamento de ações no campo da segurança pública.

\section{Metodologia}

A metodologia fundamentou-se em uma análise de correlação entre as variáveis consideradas neste estudo, bem como na comparação entre dois modelos de regressão linear que têm o coeficiente de homicídios por 100 mil habitantes como variável dependente, caracterizados a seguir:

a) 0 modelo somente com variáveis independentes representativas de situações de pobreza/vulnerabilidade social (que acabou se transformando num modelo de regressão linear simples, como será visto a seguir), definido em função do princípio de que a ocorrência de homicídios é explicada fundamentalmente pelas situações de pobreza/vulnerabilidade social;

\footnotetext{
${ }^{2}$ Conceitualmente "Crime Organizado" ainda carece de robustez para fundamentar uma discussão, os estudos acerca desse fenômeno discutem muito mais os aspectos relacionados à dinâmica da organização, o que inclui as características, as atividades, o perfil dos participantes, entre outros, do que apresentam uma formulação conceitual. Considerando essa imprecisão e as polêmicas em torno do fenômeno, adotaremos a definição da Lei 12.850, de 2 de agosto de 2013 (Art. 1ํㅗ § 1ํ), que trata a organização criminosa como uma "a associação de 4 (quatro) ou mais pessoas estruturalmente ordenada e caracterizada pela divisão de tarefas, ainda que informalmente, com objetivo de obter, direta ou indiretamente, vantagem de qualquer natureza, mediante a prática de infrações penais cujas penas máximas sejam superiores a 4 (quatro) anos, ou que sejam de caráter transnacional" (Brasil, 2013).
} 
b) 0 modelo que, além das variáveis independentes do item anterior, introduz outra relativa à ocorrência de tráfico de drogas, considerando a hipótese, a ser testada neste trabalho, de que esse tipo de delito também é importante para explicar a ocorrência de homicídios.

Os dados estatísticos foram obtidos através da Secretaria de Segurança Pública do Estado do Pará (Pará, 2016) para os anos de 2013 a 2015, na escala de bairros, sendo inicialmente selecionados apenas aqueles situados na área continental de Belém. Em cada bairro foi calculado o coeficiente de incidência de homicídios e tráfico de drogas por 100 mil habitantes, dividindo-se a média de ocorrências anuais do período 2013-2015, para maior estabilidade dos dados, pelo número de habitantes informado pelo Censo Demográfico 2010 (IBGE, 2010), visto que não há projeção oficial de população por bairros no período intercensitário. Tal procedimento resultou em uma pequena superestimação nos coeficientes, pois os dados do fenômeno estudado são mais recentes do que os dados de população. (Tabela 1, Apêndice 1).

Por outro lado é necessário destacar que os dados, baseados no registro de ocorrências policiais, nem sempre refletem fielmente a realidade, já que estão sujeitos a omissões e erros de atribuição do local correto, neste caso, o bairro.

Foram excluídos os bairros com menos de 10.000 habitantes, para evitar o problema da instabilidade dos indicadores de eventos raros, que comumente ocorre quando se trabalha com populações reduzidas, em que pequenas diferenças nas quantidades dos eventos observados podem produzir elevadas variações no valor do indicador calculado. Este é o motivo que justifica a limitação do presente trabalho à área continental de Belém, tendo em vista que todos os bairros da área insular desse município são compostos por bairros com população menor do que 10.000 habitantes, com exceção de São João do Outeiro, que contava com 12.134 habitantes. Tal recorte territorial não trouxe maiores prejuízos aos resultados, pois os bairros da parte insular totalizam 60.039 habitantes em 2010, o que correspondia a somente 4,3\% do total da população urbana do município nesse ano (1.381.475 habitantes), conforme IBGE (2010).

Procedeu-se a realização de duas análises: geográfica e estatística. A análise geográfica partiu da construção de um sistema de informações geográficas (SIG) usando o programa QGIS, com polígonos que representam os limites dos 36 bairros considerados. Os dados estatísticos foram associados aos polígonos com vistas à construção de cartogramas que permitissem visualizar a distribuição geográfica dos dados. 0 SIG também possibilitou a geração do arquivo em formato "shp" que foi usado para verificar a existência de autocorrelação espacial, por meio do cálculo do Índice Global de Morán, realizado no programa estatístico R.

O procedimento estatístico, também executado com uso do programa $\mathrm{R}$ carregado com diversos pacotes, consistiu nas análises de correlação e de regressão linear múltipla entre uma variável dependente ("Hom100"), correspondente ao coeficiente de homicídios por 100 mil habitantes, e quatro variáveis independentes:

a. Ocorrência de casos de tráfico de drogas registrados em boletins de ocorrência policial, por 100 mil habitantes ("Traf100"), também a média dos anos de 2013 a 2015 e disponibilizados pela mesma fonte;

b. Três variáveis que representam situações de pobreza/vulnerabilidade social, baseadas em dados do Censo Demográfico 2010:

i. Percentual de domicílios com rendimento médio mensal per capita até meio saláriomínimo ("AteMeioSM"), que mensura o nível de pobreza de cada bairro;

ii. Percentual de população não branca ("PopNBranca");

iii. Percentual de domicílios monoparentais com dois ou mais moradores ("DomMonop”).

A análise de correlação foi complementada com uma análise de mediação (mediation analysis), para melhor compreensão das relações entre as variáveis, também com o uso do programa $\mathrm{R}$ carregado com o pacote "medmod".

Como última etapa, com o uso de análise de variância, realizou-se a comparação estatística entre dois modelos de regressão linear: o que contém as variáveis relativas à pobreza/vulnerabilidade social e à ocorrência de tráfico de drogas como variáveis independentes e a taxa de homicídios como variável dependente; e o que considerou apenas as variáveis relacionadas à pobreza/vulnerabilidade social como 
variáveis independentes e a taxa de homicídios como variável dependente. Se o primeiro modelo de mostrar resultados significativamente melhores (significância estatística) do que o modelo que considerou apenas os aspectos relacionados à vulnerabilidade social, a hipótese de pesquisa será corroborada; caso contrário, a hipótese será rejeitada.

\section{Conformidade dos estudos no Brasil sobre a relação homicídios e tráfico de drogas}

Criminalidade violenta e mercado ilícito de drogas são temas que atualmente ocupam importante espaço nas discussões acadêmicas, no imaginário popular e no espetáculo midiático, como uma suposição, mas provoca o sentimento de medo e de insegurança, ao mesmo tempo em que altera o padrão de vida social da população, mesmo quando não se trata de uma realidade factual ou ameaça real (Miranda, 2011).

Em termos de criminalidade violenta há um consenso entre os estudiosos (Zaluar, 1999; Pinheiro; Almeida, 2003; Misse, 2011; Miranda, 2011; Burke, 1999; Minayo, 2006; Souza, 2003; Sento-Sé, 2005) quanto ao incremento dos números de homicídios no Brasil, a partir dos anos 1980 (6.104), o que se repetiu nas três décadas seguintes, 1990 (16.588), 2000 (30.865) e 2010 (36.792), e continuou nos anos 2011 (36.737), 2012 (40.077), 2013 (40.369) e 2014 (42.291), como aponta o Mapa da Violência (Waiselfisz, 2016). A mesma fonte mostrou que as regiões brasileiras seguiram um ritmo semelhante, com ligeiras oscilações, exceto o sudeste, que vem demonstrando queda do número de homicídios, em algumas capitais, desde ao ano de 2005. (Waiselfisz \& Athias, 2005)³.

No que se refere às regiões do país é necessário considerar a diferença da lógica de organização da criminalidade, que depende dos processos distintos de cada região, e pode ser identificada através da distribuição espacial desigual da dinâmica criminal, confirmada pela queda das ocorrências de homicídios em algumas cidades do Sudeste e o aumento em cidades do Norte, do Nordeste e do Sul.

Somam-se a isso os procedimentos e os recursos governamentais e sociais, destinados ao controle da criminalidade nas diferentes regiões que, de modo geral, não demonstram mudanças significativas no padrão da segurança pública, que se mantém oscilando entre poucas ações exitosas e muitos fracassos, quanto à capacidade de tornar o país um lugar onde a população possa manter a sua rotina sem o sentimento de insegurança e o medo generalizado. A esse respeito podemos citar os resultados do acompanhamento do Observatório da Intervenção do Centro de Estudos de Segurança e Cidadania $\mathrm{CESeC}^{4}$ sobre a intervenção militar no Rio de Janeiro ${ }^{5}$ que indicam a permanência e, em alguns casos, o aumento dos números de crimes na cidade. Uma pesquisa do Fórum Brasileiro de Segurança Pública, realizada em março de 2018, com moradores do Rio de Janeiro, mostrou que $92 \%$ dos pesquisados têm medo de ser atingidos por bala perdida. (Ramos, 2018).

Quando se trata da Região Norte, o estudo de Deluchey (2017) sobre as desigualdades regionais na segurança pública da Região Norte Amazônica mostrou, com base nos dados do Datasus, que o crescimento dos homicídios, no período entre 2000 e 2010, apresentou o maior aumento do Brasil em volume (132\%) e da taxa de crescimento (88,6\%), um aumento que se concentrou principalmente no Pará.

Além da relevância dos dados mostrados na pesquisa, o autor refletiu sobre as desigualdades de recursos entre as regiões brasileiras, mostrando que um dos pontos cruciais dessa desigualdade é o orçamento destinado à segurança pública. 0 orçamento da Região Norte, geralmente é menor do que os das outras regiões e, além disso, o Norte gasta muito mais com as despesas correntes e com a folha de pagamento dos agentes estaduais, em detrimento às despesas com a segurança, o que certamente interfere no controle dos crimes, em especial o tráfico de drogas e os homicídios.

\footnotetext{
${ }^{3}$ Estudo que mostrou a redução dos indicadores de violência do Estado de São Paulo.

${ }^{4}$ O CESeC é um Centro de estudos que se dedica ao campo da segurança pública no Brasil e foi fundado em 2000, pela Fundação Cândido Mendes. Criou o Observatório da Intervenção para acompanhar e divulgar os desdobramentos, impactos e violações de direitos decorrentes da intervenção federal no Rio de Janeiro.

${ }^{5}$ A intervenção federal na segurança pública do Estado do Rio de Janeiro ocorreu a partir do Decreto no 9.288, de 16 de fevereiro de 2018 , assinado pelo presidente Michel Temer, com o objetivo de garantir o retorno à ordem pública e impedir o avanço da criminalidade no estado, que se acentuou em 2016 e 2017. A intervenção contou com um interventor militar e o emprego das Forças Armadas que buscavam, através das suas operações, a "garantia da lei e da ordem" (GLO). Os resultados demonstraram aumento do número de homicídios decorrentes de ação policial no estado, falta de iniciativas de investigação e de esclarecimento desses eventos (Rodrigues \& Armstrong, 2019).
} 
Quando se referiu ao cenário dos homicídios, Deluchey (2017) valorizou a realização de análises sobre as causas e a forma como essa questão está sendo tratada pelos governantes, além de sugerir ações que dependem da participação ativa e democrática dos setores institucionais e da comunidade cidadã, atores sociais que devem ser movidos pelo desejo de criar um espaço público de debates e de intervenção na segurança, com vistas à garantia da vida, uma iniciativa ainda pouco experimentada no Brasil e menos ainda na Região Norte, que demonstra limitada capacidade de organização social e mobilização.

Ainda tratando sobre homicídios na Região Norte, o Mapa da violência (Waiselfisz, 2016) mostrou que entre os Estados da Região, o Pará e o Amazonas concentraram os maiores números desse crime cometido por arma de fogo, entre 2004 e 2014. Esse mesmo ritmo se repetiu nas suas capitais, Belém e Manaus, respectivamente. Acrescenta-se ainda que em 2010 a Região Metropolitana de Belém-RMB6 registrou a segunda mais alta taxa de homicídios $(80,2$ por 100 mil habitantes), entre as regiões metropolitanas brasileiras, com um crescimento de 383,5\%, no decorrer dos anos 2000 (Waiselfisz, 2011b).

Enquanto várias pesquisas reúnem dados sobre o crescimento dos homicídios no Brasil, as informações relacionadas ao tráfico de drogas ainda são pontuais e dependentes de outros dados acessíveis. A escassa produção de dados sobre as ocorrências de tráfico de drogas faz dos estudos que buscam encontrar explicações para a criminalidade violenta, importantes aliados quando se busca verificar se há uma conexão entre os homicídios e a expansão do comércio ilegal de drogas. Pesquisas realizadas nas cidades de Belo Horizonte (Beato Filho et al, 2001), Rio de Janeiro (Dirk; Moura, 2017) e Uberlândia (Britto, 2017) são valiosas referências.

Na cidade de Belo Horizonte, a pesquisa levantou o total de 1.258 homicídios no período entre 1995 e 1999 e utilizou um programa denominado SaTScan para identificar os conglomerados de risco de mortalidade mais elevado, tomando os 240 bairros da cidade como unidades geográficas. Nesse conjunto foram identificados apenas dez conglomerados, com risco maior de homicídios, quase todos em favelas. Os autores concluíram que se existem 85 favelas ao todo, não são as condições socioeconômicas as responsáveis pelos conglomerados de homicídios, e sim o fato dessas regiões serem assoladas pelo tráfico e violência, associada ao comércio de drogas (Beato Filho et al, 2001).

No Rio de Janeiro, o estudo se propôs verificar as principais circunstâncias ou motivações das ocorrências de letalidades violentas na Região Metropolitana no ano de 2014. Para isso, foi sorteada uma amostra de 400 registros de ocorrência, por Amostra Aleatória Simples (AAS), contendo 447 vítimas, com intervalo de confiança de $95 \%$ e margem de erro de $4,7 \%$ para o total de vítimas; na sequência foi lida cada peça do inquérito e cada um dos registros. 0 resultado colocou o tráfico de drogas no topo da lista das motivações e das circunstâncias da letalidade violenta. Duas importantes conclusões aparecem nesse estudo:

1) comparada à atuação das milícias, o tráfico tende a atuar de maneira mais extravagante nas mortes que produz, por esse motivo é provável "que as informações que permitem ligar um homicídio à atuação do tráfico sejam mais evidentes do que nos casos associados à milícia” (Dirk ; Moura, 2017, p. 5); 2) o tráfico de drogas aparece na pesquisa como a principal motivação das letalidades violentas, apoiado pelo poder das armas de fogo.

Em Uberlândia foi investigada a ocorrência de 679 homicídios entre 2010 e 2014, dos quais, 528 (78\%) foram relacionados ao tráfico de drogas, sobretudo ao comércio da cocaína e do crack, sendo destaque no quadro da violência da cidade, que tem como "porta de entrada" do tráfico a rodovia BR-365, que liga Uberlândia a Ituiutaba. A maioria dos homicídios ocorreu nas periferias, com a utilização de armas de fogo e envolveu homens e mulheres jovens. A violência juvenil e uso de armas de fogo são problemas marcantes em Uberlândia que já registrou um aumento de 400\% dos homicídios de jovens, no período entre 2009 e 2014. Nesse cenário, o autor chama a atenção para relação entre os homicídios, roubos e drogas, ressaltando que os roubos são praticados com o objetivo de adquirir dinheiro para comprar drogas e armas de fogo que, por sua vez são utilizadas na prática de homicídios (Britto, 2017).

Os resultados das pesquisas mencionadas sobre a ligação entre as ocorrências de homicídios e o tráfico de drogas apresentaram elementos importantes que, de certa forma, apoiam a hipótese que foi levantada neste estudo sobre a referida conexão, que ainda está cercada por muitas interrogações.

\footnotetext{
${ }^{6}$ Composta atualmente por 7 (sete) municípios (Belém, Ananindeua, Marituba, Benevides, Santa Bárbara do Pará, Santa Isabel do Pará e Castanhal), possui área de 3.569,222 km² e reúne uma população de 2. 422481 (IBGE, 2010).
} 
A cidade de Belém é contemplada por uma variada capacidade de acesso ao seu território tornando-se um lugar com grande possibilidade para a intensificação do comércio ilícito e da circulação das pessoas que participam desse tipo de atividade. A pesquisa realizada por Couto (2014) apresentou o mapa da rota do tráfico de drogas no Pará pelas vias aérea, terrestre e fluvial, destacando a importância do Estado para o fortalecimento das redes ilegais do narcotráfico, as quais criam estratégias para materializar o território do crime, ao envolverem cidades ribeirinhas se interligam à Belém pela Baía do Guajará. Por via aérea, a conexão inclui várias escalas e coloca Belém numa posição fundamental para a relação local/global. E ressaltando a importância de Belém para o funcionamento das redes ilegais, Couto destaca a conexão Belém-Abaetetuba, uma rota que se dá por vias terrestre e fluvial, dentro do próprio Estado.

Sem nos deter nas concepções disseminadas sobre a atividade ilegal do tráfico de drogas como fenômeno global e como uma cultura empresarial, fomentada pela visão capitalista, resumida em "ganhar dinheiro facilmente para consumir de modo hedonista" (Zaluar, 2010, p. 163), seguimos refletindo sobre a lógica de atuação do tráfico na cidade de Belém, com base nos estudos disponíveis.

Couto (2014) sustenta que o tráfico de drogas funciona através de redes globais e que Belém é um dos "nós" na área de trânsito da droga. Nos seus estudos sobre a rede do narcotráfico em Belém, particularmente em dois bairros de baixa renda (Guamá e Terra Firme), o autor reforça argumentos já expostos em outras pesquisas (Zaluar, 2004; Feffermann, 2006; Misse, 2011) a respeito da facilidade que o tráfico encontra para territorializar uma área que se encontra em "processo desestruturado de urbanização", com carência de serviços públicos e infraestrutura urbana, socialmente excluída e com uma população suficientemente vulnerável para se sujeitar ao seu domínio.

As áreas periféricas da cidade acolhem o tráfico de drogas que, por sua vez, se identifica com as condições que favorecem a sua reprodução, quando delas dispõe como mercados consumidores e pontos de distribuição. Ao mesmo tempo, essas áreas também podem se tornar locais de intensos e inevitáveis conflitos, para reafirmar a sujeição aos códigos previamente estabelecidos pela organização criminosa.

$\mathrm{Na}$ "territorialização perversa do tráfico", a violência se apresenta como uma característica dos bairros periféricos. A disputa de grupos rivais por áreas de influência nesses bairros transforma o cotidiano dos moradores em uma verdadeira fobópole, segundo o trabalho de Souza (2008). (Couto, 2014, p. 175).

É comum a ocorrência de homicídios motivados pelo controle de territórios em áreas de influência do tráfico de drogas; pelos "acertos de contas"7 e para garantir o próprio consumo da droga. Neste último caso, os homicídios decorrem, principalmente, do crime de latrocínio, segundo as informações da Polícia do Pará, que também confirmou o elevado número de homicídios relacionados ao tráfico de drogas, no ano de 2014, durante a pesquisa de Couto. 0 autor acrescenta que também fazem parte desse contexto as execuções de ladrões que roubam nas áreas de atuação de alguns traficantes, os quais desejam estruturar suas áreas de domínio, eliminando as interferências e com isso consolidando "a espacialidade da criminalidade violenta na periferia da metrópole". (Couto, 2014, p. 179).

\section{Análise e discussão dos resultados}

Com base nas inferências dos estudos realizados e partindo da hipótese levantada, a pesquisa buscou, nas análises geográfica e estatística, um suporte para verificar a conexão entre os homicídios e o tráfico de drogas, na cidade de Belém, entre 2013 e 2015.

\footnotetext{
${ }^{7}$ Expressão que está relacionada ao funcionamento do mercado das drogas ilícitas e indica uma tarefa que já faz parte do modelo de gestão dessa atividade. Corresponde ao ato de matar que já está inserido na lógica de gerenciamento do tráfico de drogas no varejo (Vilela; Barros, 2016).
} 


\section{Análise geográfica}

A Figura 1 mostra a distribuição espacial da variável dependente - número de homicídios por 100 mil habitantes (Hom100) - nos bairros da área continental do município de Belém, excluídos aqueles de população inferior a 10.000 habitantes.

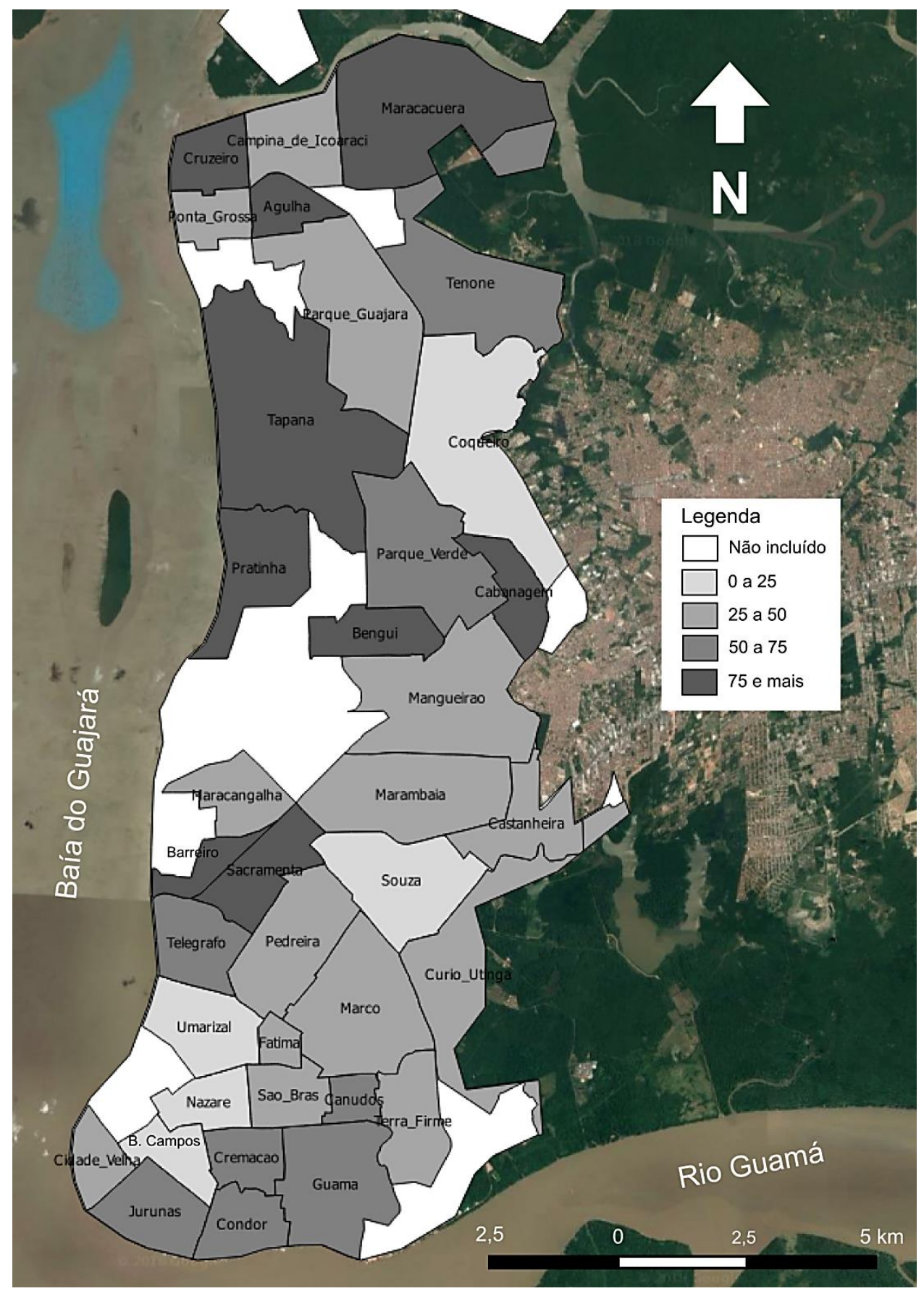

Figura 1 - Distribuição espacial do número de homicídios por 100 mil habitantes, área continental de Belém, média $2013-2015$. Fonte: Autores (2018), com base em dados da SEGUP-PA, (2016).

Percebe-se na figura que há alguns agrupamentos espaciais da variável. Na parte central da Primeira Légua Patrimonial - PLP, nas terras altas, há um conjunto de três bairros - Batista Campos, Nazaré e Umarizal - pertencentes ao estrato inferior (até 25) da variável Hom100, que são os três bairros de rendas mais altas do município. No segundo estrato mais elevado - mais de 25 a 50 homicídios - ocorre um agrupamento de oito bairros: Castanheira, Curió-Utinga, Fátima, Marambaia, Mangueirão, Marco, Pedreira e São Brás. Tal agrupamento é parcialmente interrompido pelo bairro do Souza, onde há forte presença de 
residências de militares e o coeficiente de homicídios é baixo. No terceiro estrato (mais 50 a 75 homicídios), agrupam-se quatro bairros situados nas terras baixas e de baixa renda ao sul da PLP - Condor, Jurunas, Cremação, Jurunas e Guamá (o bairro mais populoso de Belém) -, aos quais se junta o bairro de Canudos. Finalmente, no estrato mais elevado ( 75 homicídios e mais), notam-se dois agrupamentos de dois bairros cada: Barreiro e Sacramenta e Pratinha e Tapanã.

A presença de tais agrupamentos levanta a necessidade de verificar a existência ou não de autocorrelação espacial relevante, o que, em caso positivo, torna necessária a construção de um modelo de regressão que incorpore essa característica. Para isso, calculou-se o índice global de Morán, cujo valor foi de $-0,021$, que pode ser considerado muito baixo. Dessa forma, pode-se avançar na construção do modelo de regressão múltipla sem levar em conta a questão da autocorrelação espacial, que será desenvolvido na próxima seção.

Os agrupamentos em questão estão relacionados aos dois principais padrões de segregação socioespacial existentes na área continental de Belém. Na PLP, a tal segregação ocorre entre os moradores das terras altas, de rendas alta e média, e os das baixadas, onde predominam as rendas baixas. Essa configuração geográfica acaba se refletindo na distribuição espacial das taxas de homicídio: os bairros situados total ou predominantemente nas terras altas - Batista Campos, Cidade Velha, Nazaré, São Brás e Marco - registraram coeficientes de homicídios situados nos dois estratos mais baixos. Juntam-se a esses bairros o Umarizal - que, apesar de ter boa parte do seu território situado em cotas baixas, tem um padrão de ocupação urbana bem diferente das baixadas - e o de Fátima, parte do qual formado por antigas áreas de baixadas.

Já os bairros da PLP onde há expressiva presença de áreas de baixadas registram coeficientes de homicídios pertencentes aos dois estratos mais altos. Portanto, parece clara a relação existente entre a ocorrência de homicídios e as condições de pobreza/vulnerabilidade social, além do contraste entre as condições urbanas das áreas pesquisadas.

Essa configuração espacial da PLP - dois conjuntos de bairros com elevados coeficientes de homicídio separados por um grupo com baixos coeficientes - contribuiu para reduzir a autocorrelação espacial.

Outro padrão de segregação socioespacial é o centro-periferia, onde famílias de alta renda moram no centro e de rendas baixa e média-baixa na periferia. Ainda que haja alguns condomínios fechados de alta renda na periferia de Belém, a maioria dos moradores dessa parte da cidade aufere rendas baixa ou médiabaixa. Aqui, também, há uma clara separação espacial da ocorrência de homicídios. Enquanto no interior da PLP há apenas dois bairros no estrato de valores mais altos (75 homicídios por 100 mil moradores e mais) - Barreiro e Sacramenta - na periferia do município existem sete bairros nessa condição: Agulha, Benguí, Cabanagem, Cruzeiro, Maracacuera, Pratinha e Tapanã. Junta-se a estes o bairro do Parque Verde, com valores pertencentes ao terceiro estrato ( 50 a 75 homicídios), ficando definida, então, uma grande área periférica com elevada incidência de homicídios.

Portanto, a elevada criminalidade em áreas de rendas baixas de Belém também está presente em outras cidades do país, conforme mostram os estudos citados anteriormente.

\section{Análise estatística}

Considerando que a análise dos dados se baseia na construção de um modelo de regressão linear múltipla tendo como variável dependente o coeficiente de homicídios por 100 mil habitantes (Hom100), o primeiro passo foi testar o grau de normalidade dessa variável, algo importante para que o modelo chegue a resultados consistentes. A análise do histograma (Figura 2) mostrou que a distribuição é fortemente assimétrica à direita, com muitos valores situados na parte inferior da distribuição e alguns poucos casos no extremo superior, que correspondem aos bairros mais violentos. Para verificar a existência ou não de normalidade, foi utilizado o teste Shapiro-Wilk, cujo resultado rejeitou a hipótese nula da normalidade: o valor do teste foi de 0,901 e o valor-p igual a 0,00367.

Diante disso, foi necessário adotar um procedimento para normalizar os dados da variável dependente. Tendo em vista que a variável representa uma contagem de casos (por 100 mil habitantes), usou-se a raiz quadrada dos valores ("sqrtHom100") para fins de normalização. 0 teste Shapiro-Wilk foi repetido para a 
nova variável dependente e a hipótese nula da normalidade não foi rejeitada: 0,972 foi o valor do teste e 0,5054 o valor-p.

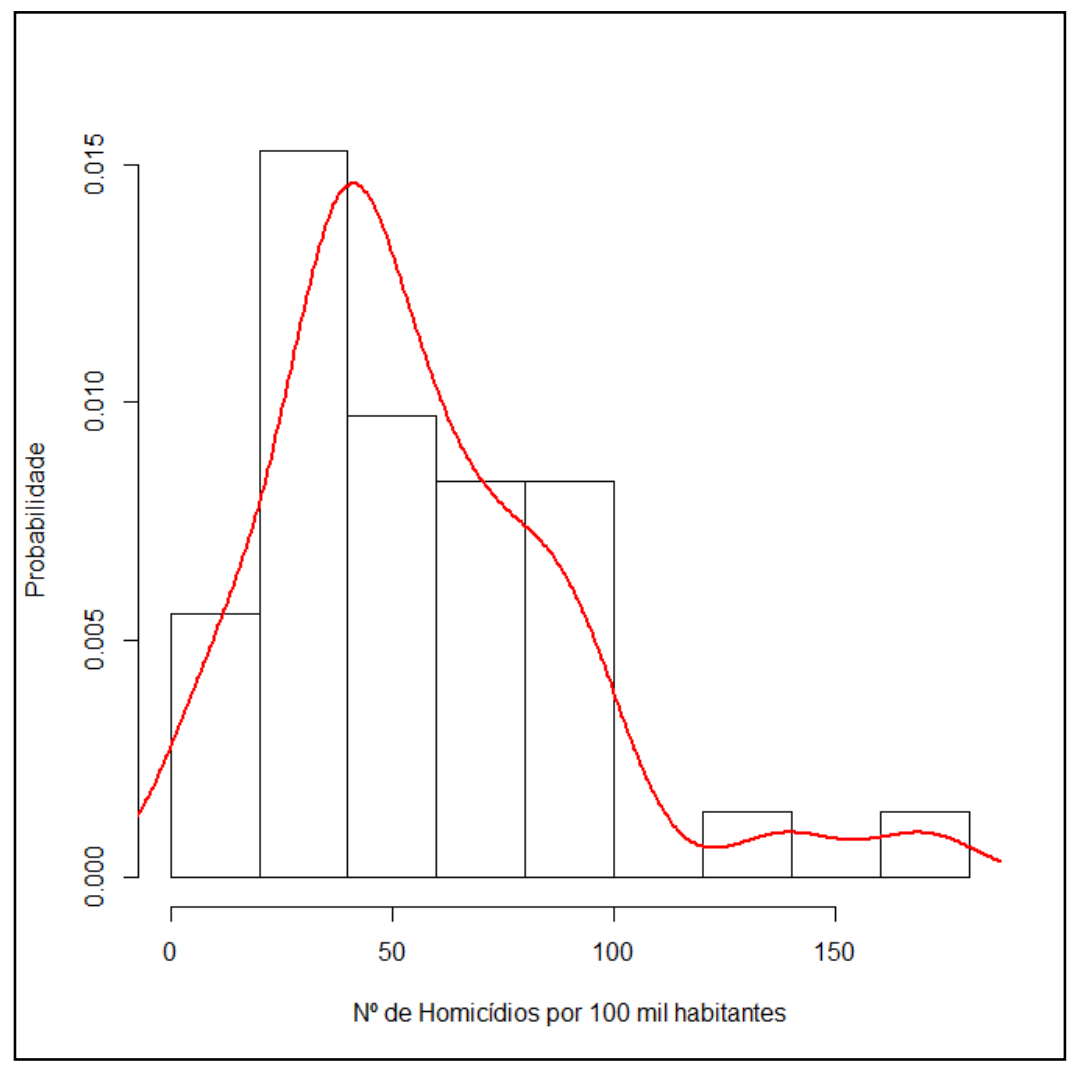

Figura 2 - Histograma (probabilidades) do número de homicídios por 100 mil habitantes. Fonte: Autores (2018).

A Figura 3 apresenta a matriz de coeficientes de correlação e outras informações importantes sobre as correlações entre todas as variáveis inicialmente consideradas neste estudo.

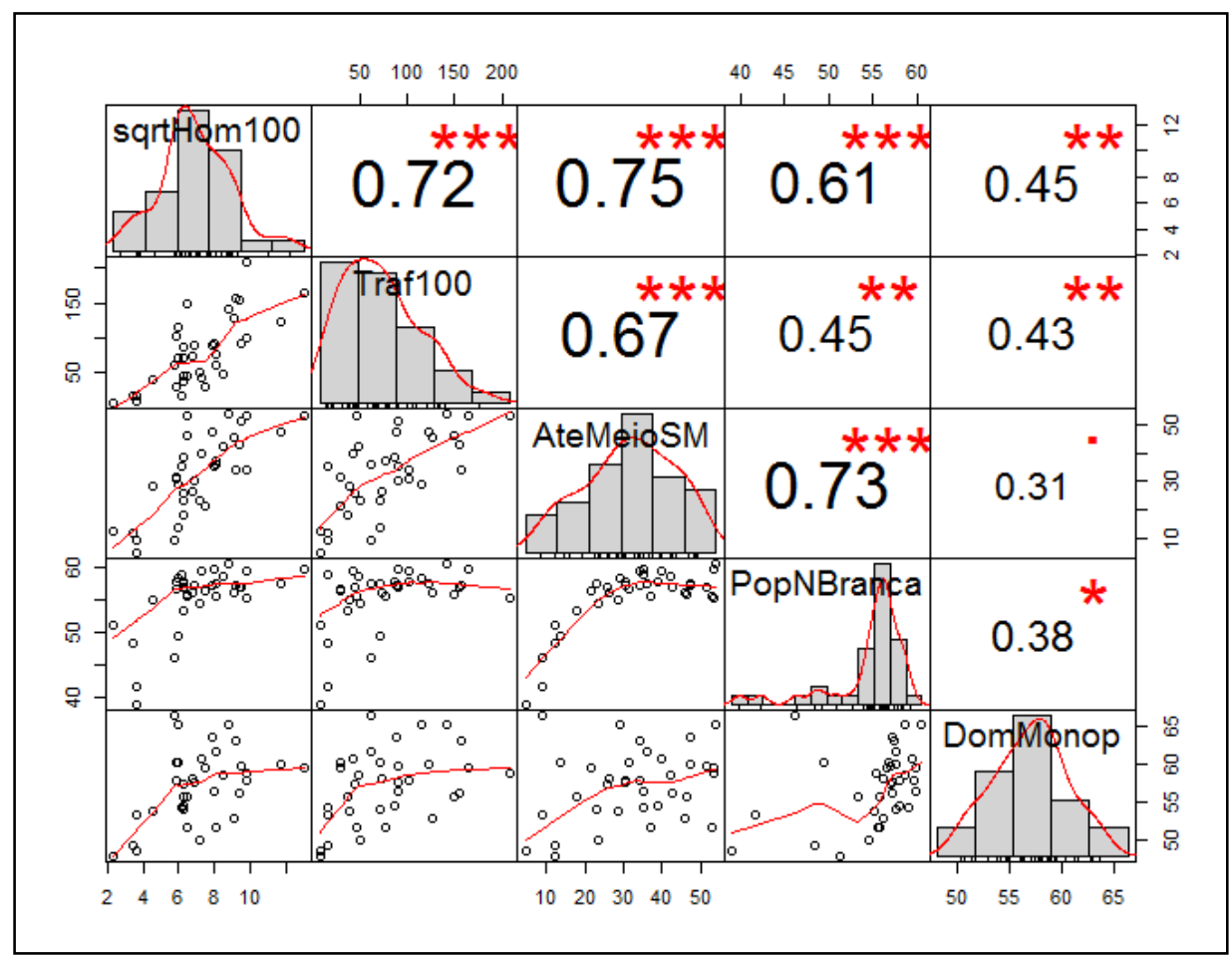

Figura 3 - Matriz de coeficientes de correlação e outras informações. Nota: valores-p: *** $0 ;{ }^{* *} 0,001 ; * 0,01 ; e^{*} 0,05$. Fonte: Autores (2018). 
Com isso a distribuição da variável sqrtHom100 ficou mais próxima da curva normal, como mostra a Figura 3. A mesma figura mostra também que todas as correlações entre as variáveis têm significância estatística, com valor-p=0,05 ou menos. Há três coeficientes da variável dependente sqrtHom 100 que podem ser considerados moderadamente fortes: 0,75 com o percentual de domicílios onde a renda média domiciliar per capita é igual ou menor a meio salário mínimo (AteMeioSM); 0,72 com o número de casos de tráfico de drogas por 100 mil habitantes (Traf100); e 0,61 com o percentual de população não branca. (PopNBranca); e 0,45, que pode ser considerado fraco tendendo a moderado, com percentual de domicílios monoparentais com dois ou mais moradores (DomMonop).

Isto significa que as quatro variáveis escolhidas - uma para representar a ocorrência de um delito específico e três para representar situações de pobreza/vulnerabilidade social - estão com associações relevantes e estatisticamente significativas (ao nível de $\mathrm{p}=0,05$ ) no tocante à ocorrência de homicídios. Contudo, o expressivo valor da correlação de PopNBranca com sqrtHom100 $(0,61)$ deve ser visto com cuidado. Isto porque a análise de mediação entre as variáveis mostrou que, num modelo de regressão linear tendo a primeira variável e AteMeioSM como independentes e sqrtHom100 como dependente, o efeito direto de PopNBranca sobre SqrtHom100 é de apenas 20,5\% do coeficiente de correlação total, sendo os restantes $79,5 \%$ decorrentes da mediação feita por AteMeioSM. 0 mesmo pode ser dito no tocante ao coeficiente de correlação entre DomMonop e sqrtHom100 $(0,45)$ : somente 12,2\% dos efeitos da primeira sobre a correlação com a segunda são diretos, enquanto os demais $87,8 \%$ se referem a efeitos indiretos, mediados pela variável representativa de situações de pobreza (AteMeioSM).

Ressalte-se que a definição das relações de causalidade entre as variáveis decorre de conhecimentos oriundos das ciências sociais e não da análise estatística, visto que a existência de uma correlação forte entre duas variáveis não significa, necessariamente, que haja relação de causalidade entre elas, haja vista que esta pesquisa é de caráter observacional e não experimental.

0 modelo de regressão inicialmente definido, de sqrtHom100 como variável dependente e todas as variáveis relacionadas à vulnerabilidade social como independentes, apresentou os resultados mostrados na Tabela 2.

Tabela 2 - Parâmetros do modelo de regressão múltipla com todas as variáveis

\begin{tabular}{ccccc}
\hline Variável & Coefic. & Erro Padrão & Valor ${ }^{t}$ & Nível Signif. \\
\hline (Intercepto) & $-2,746502$ & 3,881681 & $-0,708$ & 0,4845 \\
AteMeioSM & 0,062924 & 0,028842 & 2,182 & 0,0368 \\
Traf100 & 0,015871 & 0,006536 & 2,428 & 0,0212 \\
PopNBranca & 0,053529 & 0,07169 & 0,747 & 0,4609 \\
DomMonop & 0,063309 & 0,055719 & 1,136 & 0,2646 \\
\hline \multicolumn{5}{r}{ Fonte: Autores (2018). }
\end{tabular}

O modelo apresentou uma variância explicada ajustada de 64\%, o que é bastante razoável para modelos de regressão usados em ciências humanas. Contudo, a Tabela 2 mostra que os parâmetros definidos para duas variáveis explicativas não são significativos: PopNBranca e DomMonop, que apresentam valores-p bem maiores do que 0,05 , o mesmo ocorrendo com o intercepto, o que sugere a eliminação dessas variáveis do modelo. 0 principal motivo para isso é a elevada multicolinearidade entre as variáveis, algo que pode ser atestado pelo gráfico apresentado na Figura 3. A análise de mediação ajuda a compreender este fenômeno: a influência das variáveis PopNBranca e DomMonop sobre a correlação com sqrtHom100 ocorre principalmente de forma indireta, mediada pela variável AteMeioSM.

0 próximo passo foi excluir do modelo de regressão as variáveis explicativas não relevantes para o modelo de regressão. Para dar maior segurança a essa operação, usou-se, o procedimento step wise, o qual considera o Critério de Informação de Akaike (AIC). 0 modelo resultante excluiu a variável PopNBranca, mas manteve a variável DomMonop.

\footnotetext{
${ }^{8}$ O’Rourke e Hatcher (2013) qualificam assim os coeficientes de correlação (positiva ou negativa): 1,0 - Perfeita; 0,8 - Forte; 0,5 - Moderada; 0,2 - Fraca; e 0,0 - Sem correlação.
} 
Esse primeiro modelo reduzido teve praticamente a mesma variância explicada ajustada do anterior $(64,5 \%)$, mas a variável DomMonop continuou a não ter significância estatística, com valor-p igual a 0,1681. Diante disso, eliminou-se também essa variável do modelo de regressão múltipla e o modelo definitivo passou a ter apenas duas variáveis independentes: AteMeioSM e Traf100. Dessa forma, duas das três variáveis que representavam situações de vulnerabilidade social foram excluídas, permanecendo apenas a que mensura a incidência de pobreza.

O modelo definitivo alcançou variância explicada ajustada de $63,4 \%$ e os resultados mostrados na Tabela 3. Percebe-se que as duas variáveis e o intercepto têm elevada significância estatística, considerando os valores-p obtidos.

Tabela 3 - Parâmetros do modelo de regressão múltipla com duas variáveis

\begin{tabular}{ccccc}
\hline Variável & Coef. & Erro Padrão & Valor $\dagger$ & Nível Signific. \\
\hline (Intercepto) & 3,179873 & 0,580669 & 5,476 & $4,52 \mathrm{e}-06$ \\
AteMeioSM & 0,078028 & 0,021995 & 3,547 & 0,00119 \\
Traf100 & 0,017945 & 0,006184 & 2,902 & 0,00656 \\
\hline \multicolumn{5}{c}{ Fonte: Autores, 2018. }
\end{tabular}

O modelo final de regressão múltipla ficou assim definido conforme a Equação 1:

$$
\operatorname{sqrtHom} 100=3,18+0,078 * \text { AteMeioSM }+0,018 * \text { Traf100 }
$$

O próximo passo foi testar a consistência do modelo. Testaram-se três pressupostos a serem atendidos por modelos de regressão ordinária de mínimos quadrados com o uso do pacote "gvlma" rodando no programa R: assimetria, curtose e heterocedasticidade. Todos foram considerados aceitáveis no modelo proposto.

As duas variáveis do modelo também foram submetidas ao teste de Fator de Inflação de Variância (VIF), que mensura o grau de multicolinearidade, ou seja, o grau em que cada variável independente é explicada pelas outra(s) variável(is) independente(s). 0 resultado foi 1,8054 para ambas as variáveis.

Não há consenso na literatura sobre o patamar a partir do qual o valor do VIF requer adequações no modelo para diminuir o problema da multicolinearidade; Garson (2012) sugere que este valor seja 4. Tomando por base este critério, o modelo mostrou-se adequado.

A Figura 4 apresenta quatro gráficos que detalham outra etapa do diagnóstico do modelo de regressão: a análise dos seus resíduos. 0 gráfico "Residuals vs Fitted", na Figura 4, mostra que os resíduos não seguem um padrão de movimento definido, que possa ser modelado por outra função matemática; portanto, a função linear mostrou-se adequada para representar a relação entre as variáveis. 0 gráfico "ScaleLocation", que exibe o grau de uniformidade da variância ao longo dos resíduos, demonstra a presença de pequena heterocedasticidade, visto que há uma tendência persistente de crescimento da variância dos resíduos no lado direito do gráfico, o que não é suficiente para invalidar o modelo. 0 gráfico "Normal Q-Q" deixa claro os resíduos seguem, em geral, uma distribuição normal, mas os casos 4 (Bengui), 5 (Cabanagem) e 35 (Terra Firme) apresentam valores elevados, sendo os dois primeiros positivos (i.e., os valores previstos pelo modelo estavam bem abaixo da realidade) e o terceiro, negativo (valor previsto bem acima do dado real).

O gráfico "Residuals vs Leverage" mostra que todos os resíduos padronizados têm distância de Cook menor do que 0,5 , indicando que nenhum dos casos considerados teria forte influência sobre os demais valores preditos caso fosse excluído do modelo. 


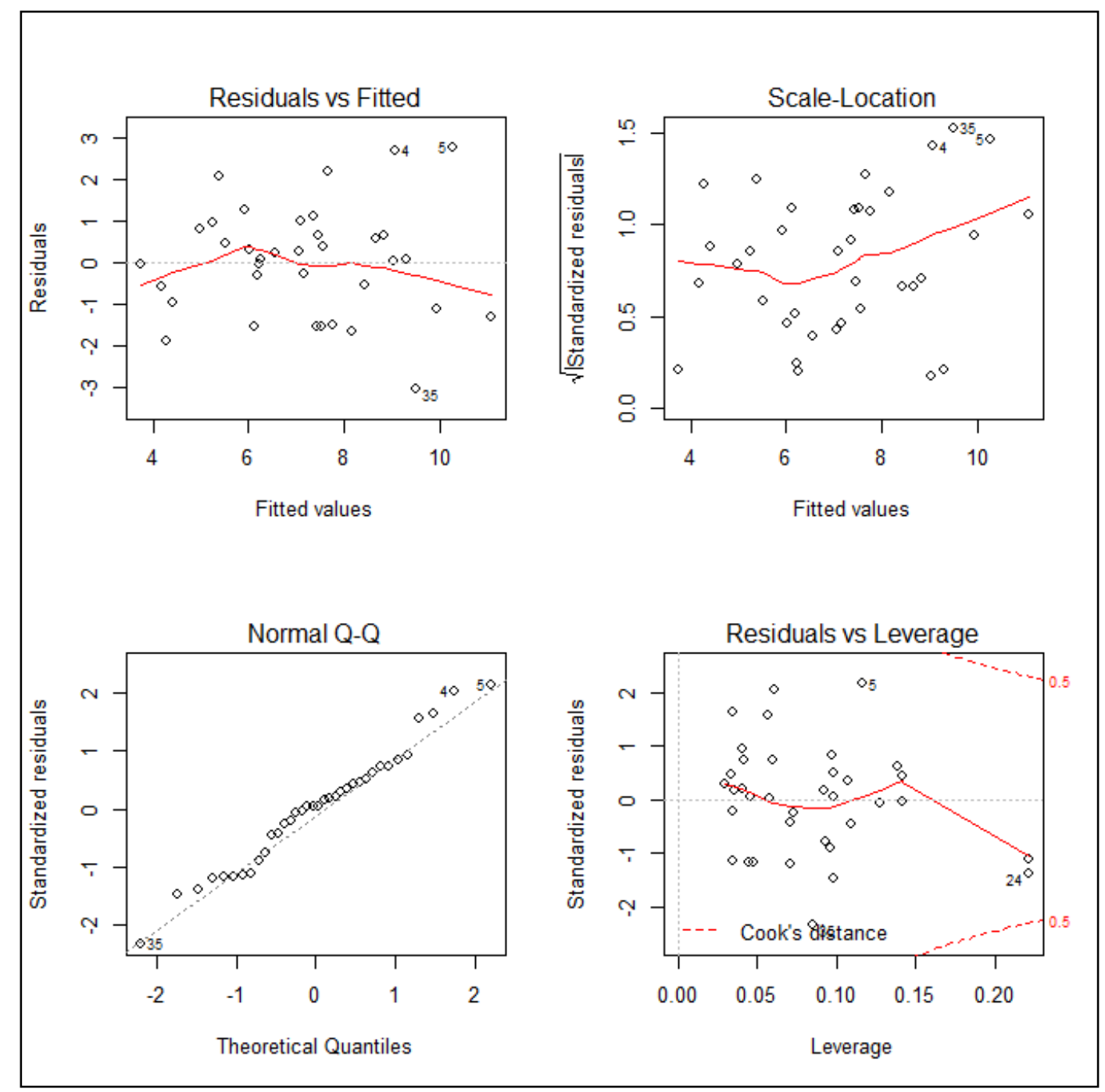

Figura 4 - Gráficos para diagnóstico do modelo definitivo de regressão linear. Fonte: Autores (2018).

À luz da análise estatística feita até aqui, pode-se considerar que o modelo de regressão linear múltipla com duas variáveis se mostrou válido para explicar a ocorrência de homicídios nos bairros considerados neste estudo.

O próximo passo foi verificar se esse modelo com duas variáveis é melhor que o modelo de regressão simples somente com AteMeioSM como variável independente. Este segundo modelo apresentou a variância explicada ajustada de 55,5\%. Portanto, o modelo simples, considerando apenas a pobreza, explica bem menos que o modelo onde a pobreza está associada ao tráfico de drogas (Traf100); neste caso, a variância explicada ajustada foi de $63,4 \%$. Ou seja, houve um acréscimo de quase $8 \%$ de variância explicada.

A análise de variância entre os dois modelos sob comparação constitui um teste mais rigoroso para aferir se o modelo com duas variáveis independentes (AteMeioSM e Traf100) é realmente melhor do que o modelo somente com a variável AteMeioSM. Os resultados deste teste estão apresentados na Tabela 4. 0 erro representado pela soma dos quadrados dos resíduos reduziu de 76,6 para $61 \mathrm{com}$ a inserção de Traf100, o que implica uma queda de 15,6. 0 valor de F alcançou 8,4. Tais resultados indicam que a variável Traf100 acrescentou ao modelo de uma variável um percentual suficiente de variância explicada para rejeitar a hipótese nula de que o coeficiente da mesma é zero. 0 nível de significância foi de 0,0066 , ou seja, $\mathrm{p}<0,01$. 
Tabela 4 - Análise de variância dos modelos de regressão de uma e duas variáveis

\begin{tabular}{ccccccc}
\hline Modelo & Grau liberd. resid. & Soma quadr. resíd. & Grau liberd. & Soma quadr. & F & Nível Signif. \\
\hline Uma var. & 34 & 76,6 & - & - & - & - \\
Duas var. & 33 & 61,0 & 1 & 15,6 & 8,4 & 0,0066 \\
\hline
\end{tabular}

Fonte: Autores, 2018.

Dessa forma, os coeficientes de homicídios por 100 mil habitantes dos bairros da área continental de Belém são explicados de forma mais consistente pelo modelo de regressão linear múltipla, que associa pobreza e tráfico de drogas, do que pelo modelo de regressão linear simples, que considera somente o indicador de pobreza, o que corrobora a hipótese adotada no presente trabalho: a elevada taxa de homicídios da capital paraense está relacionada não somente às situações de pobreza/vulnerabilidade social, mas também à incidência do tráfico de drogas.

\section{Considerações finais}

Ainda que haja aceitação sobre a relação entre situações de pobreza e ocorrência de homicídios, esta pesquisa mostrou que o tráfico de drogas surge como outro fator com importante potencial para explicar a distribuição espacial dos homicídios na cidade de Belém.

A segregação social que se impõe a determinadas áreas da cidade está relacionada à expansão do espaço urbano e às diversas interferências na produção desse espaço. Nota-se que nas áreas mais desprovidas de recursos e serviços urbanos e onde também se concentra a população mais carente do ponto de vista econômico e social, o crime encontra ambiente favorável para se instalar e permanecer de forma dominante, controlando territórios e estabelecendo regras de conduta social, sem encontrar barreiras para a sua ampliação.

Os dados desse estudo mostraram que entre 2013 e 2015, os homicídios convergiram para as áreas pobres de Belém não somente por causa da situação de pobreza nelas existente, mas porque também há, nessas áreas, uma tendência do tráfico de drogas de torná-las fonte de recursos e de reprodução dessa atividade. E devido à própria estrutura que a organização criminosa demanda, os conflitos acabam se intensificando em função da disputa e da concorrência por esse tipo de comércio e ocorrem os desvios entre alguns participantes da organização que, em geral, são punidos com a morte, para servir de exemplo aos demais.

A configuração física do sítio onde está situada a área continental do município de Belém constitui fator fundamental para explicar a configuração espacial dos padrões de segregação socioespacial aí existente: entre terras altas e terras baixas, no interior da Primeira Légua Patrimonial; e entre centro e periferia. Por seu turno, essa segregação socioespacial é uma importante causa para elucidar a incidência de homicídios. Contudo, o modelo de regressão validou a hipótese de que as situações de pobreza, aliadas à elevada ocorrência de tráfico de drogas, explicam melhor os diferentes níveis de homicídios do que apenas a pobreza isoladamente.

Refletiu-se que os resultados dessa pesquisa ainda estão cercadas por suposições sobre a relação entre as ocorrência de homicídios e o tráfico de drogas, mas já permite inferir que a pobreza não é o único determinante dos homicídios na área pesquisada. Além disso, o conhecimento do resultado de pesquisas que foram realizadas sobre a atividade do tráfico de drogas em áreas pobres, de outras cidades brasileiras reforçou a ideia pressuposta de que o crescimento dos homicídios está intimamente ligado a atuação criminosa do tráfico nas áreas com elevada incidência de pobreza.

\section{Referências}

Beato Filho, C. C. ; Assunção R. M.; Silva, B. F. A.; Marinho, F.C.; Reis, I. A.; Almeida, M. C. M. (2001). Conglomerados de homicídios e o tráfico de drogas em Belo Horizonte, Minas Gerais, Brasil, de 1995 a 1999. Cadernos de Saúde Pública, 17(5), 1163-1171. Recuperado em 20 de maio de 2018 de http://www.scielo.br/pdf/csp/v17n5/6324.pdf 
Brasil (2013). Lei no 12.850, de 2 de agosto de 2013. Define organização criminosa e dispõe sobre a investigação criminal, os meios de obtenção da prova, infrações penais correlatas e o procedimento criminal; altera o Decreto-Lei $\mathrm{n}^{\mathbf{0}}$ 2.848, de 7 de dezembro de 1940 (Código Penal); revoga a Lei no 9.034, de 3 de maio de 1995; e dá outras providências. Disponível em: <http://www.planalto.gov.br/ccivil_03/_ato2011-2014/2013/lei/l12850.htm>. Acesso em 4 maio 2019.

Britto, C. Q. (2017). Violência e homicídios relacionados ao tráfico de drogas, em Uberlândia - MG (Tese de Doutorado). Programa de Pós-Graduação em Geografia, Universidade Federal de Uberlândia (MG).

Burke, P. Violência urbana e civilização. In: Oliveira, N. V. (1999). Insegurança pública: reflexões sobre a criminalidade e a violência urbana. São Paulo: Instituto Fernand Braudel de Economia Mundial.

Cerqueira, D. ; Lima, R. S.; Bueno, S.; Valencia, L. I.; Hanashiro, O.; Machado, P. H. G.; Lima, A. S. (2017). Atlas da violência 2017. Rio de Janeiro: Instituto de Pesquisa Econômica Aplicada - Ipea/ Fórum Brasileiro de Segurança Pública- FBSP.

Couto, A. C. O. (2014). A geografia do crime na metrópole: das redes ilegais a "territorialização perversa" na periferia de Belém. Belém: EDUEPA.

Deluchey, J. Y. (2017). Para além das desigualdades regionais na segurança pública: um olhar na Região Norte Amazônica. In: Zimerman, A. (Org.). Políticas de segurança pública. Santo André (SP): Universidade Federal do ABC.

Dirk, R. \& Moura, L. (2017). As motivações nos casos de letalidade violenta da Região Metropolitana do Rio de Janeiro. Cadernos de Segurança Pública, 9(8). Recuperado em 3 de junho de 2018 de http://www.isprevista.rj.gov.br/download/Rev20170802.pdf. Acesso em 20 jan. 2018.

Engel, C. L. et al. (2015). Diagnóstico dos homicídios no Brasil: subsídios para o Pacto Nacional pela Redução de Homicídios. Brasília-DF: Ministério da Justiça/ Secretaria Nacional de Segurança Pública.

FBSP - Fórum Brasileiro de Segurança Pública (2016). Anuário Brasileiro de Segurança Pública, ano 10. São Paulo: FBSP.

Feffermann, M. (2006). Vidas arriscadas: o cotidiano dos jovens trabalhadores do tráfico. Petrópolis: Vozes.

Garson, G. D. (2012). Testing statistical assumptions. Ashoboro (US): Statistical Publishing Association.

IBGE. Instituto Brasileiro de Geografia e Estatística (2010). Censo Demográfico 2010. Disponível em: <https://www.ibge.gov.br/estatisticas/sociais/saude/9662-censo-demografico-2010.html?=\&t=destaques>. Acesso em: 16 jan. 2018.

IBGE. Instituto Brasileiro de Geografia e Estatística (2017). Estimativas populacionais dos municípios para 2017. Diretoria de Pesquisas - DPE, Coordenação de População e Indicadores Sociais - COPIS.

Minayo, M.C.S. (2006). Violência e saúde. Rio de Janeiro: Editora Fiocruz.

Miranda, M. M. (2011). Sociedade, violência e políticas de segurança pública: da intolerância à construção do ato violento. Revista Eletrônica Machado Sobrinho, edição 3, jan-jul, Recuperado em 3 de junho de 2018 de http://www.machadosobrinho.com.br/revista_online/publicacao/artigos/Artigo01REM3.pdf.

Misse, M. (1993). Crime e Pobreza: novos enfoques, velhos problemas. Seminário Brasil em perspectiva: os anos 90. Departamento de Pesquisas Sociais do IFCS-UFRJ, Rio de Janeiro, 26 agosto.

Misse, M. (1995). Cinco Teses Equivocadas sobre a Criminalidade Urbana no Brasil: uma abordagem crítica, acompanhada de sugestões para uma agenda de pesquisas. Seminário Violência ou Participação Social no Rio de Janeiro, IUPERJ, Rio de Janeiro, 17 abril.

Misse, M. (2011). As drogas como problema social. Revista Periferia, v. 3, n.2, jul./dez.

O’Rourke, N.; Hatcher, N. (2013). A step-by-step approach to using SAS for factor analysis and structural equation modelling (2a ed., v. 1). Cary, (US): SAS Institute.

Pará. Secretaria de Segurança Pública do Pará - SEGUP (2016). Banco de Dados da Secretaria de Inteligência e Análise Criminal. Homicídio, Roubo e Tráfico - Belém.xlsx [arquivo eletrônico]. Belém (PA).

Pinheiro, P. S. : Almeida, G. A. (2003). Violência urbana. São Paulo: Pubfolha. 
Ramos, S. (coord.) (abr. 2018). À deriva: sem programa, sem resultado, sem rumo. Rio de Janeiro: Observatório da Intervenção/CESec. Recuperado em 3 de junho de 2018 de https://www.ucamcesec.com.br/projeto/observatorio-daintervencao/. 2 jul. 2018.

Reis, E. P.; Schwartzman, S. (2004). Pobreza e exclusão social, aspectos sociopolíticos. Trabalho preparado por solicitação do Banco Mundial, como contribuição para um estudo em andamento sobre a exclusão social no Brasil. In: Schwartzman, S. (2004). As causas da pobreza. São Paulo, Editora FGV.

Rodrigues, R. I. \& Armstrong, K. (2019). A intervenção federal no Rio de Janeiro e as organizações da sociedade civil. Relatório de Pesquisa. Instituto de Pesquisa Econômica e Aplicada- IPEA, Rio de Janeiro.

Santos, J. O. (2015). Relações entre fragilidade ambiental e vulnerabilidade social na susceptibilidade aos riscos. Mercator, Revista de Geografia da UFC, v. 14, n. 02, p.75-90, 20 jul. Disponível em:

http://www.mercator.ufc.br/mercator/issue/view/RMv14n2. Acesso em:12 maio. 2019.

Soares, L. E.; Soares, B. M.; Ribeiro, C. A. C.; Milito, C.; Silva, H. R. S.; Muniz, J.; Sento-Sé, J.T.; Rodrigues, J. A. S.; Carneiro, L. P. (1996). Violência e política no Rio de Janeiro. Rio de Janeiro: Relume Dumará.

Souza, M.L. (2003). Planejamento e gestão urbanos em uma era de medo: sobre tráfico de drogas, fragmentação do tecido sociopolítico-espacial da cidade e o encolhimento da margem manobra para a promoção de um desenvolvimento urbano autêntico. In: Carlos, A. F.; Lemos, A. I. (orgs.). Dilemas Urbanos Novas Abordagens Sobre a Cidade. São Paulo: Contexto.

Sen, A. (2008). Desigualdade reexaminada. Tradução e apresentação de Ricardo Doninelli Mendes, 2 ed. Rio de Janeiro/São Paulo: Editora Record.

Sento-Sé, J.T. (2005). Prevenção da violência: o papel das cidades. Rio de Janeiro: Civilização brasileira. (Segurança e cidadania, 3).

Schwartzman, S. (2004). As causas da pobreza. São Paulo, Editora FGV.

Vilela, T.; Barros, V.A. (2016). 0 acerto de contas no trabalho do tráfico de drogas varejista. Gerais: Revista Interinstitucional de Psicologia, v.9, n.2, Juiz de Fora, dez..

Waiselfisz, J.J. ; Athias, G. (2005). Mapa da violência de São Paulo. Brasília: UNESCO.

Waiselfisz, J. J. (2011a). Mapa da violência 2011: os jovens do Brasil. São Paulo: Faculdade Latino-Americana de Ciências Sociais (Flacso Brasil).

Waiselfisz, J. J. (2011b). Mapa da Violência 2012: os novos padrões da violência homicida no Brasil. São Paulo: Instituto Sangari.

Waiselfisz, J. J. (2016). Mapa da violência 2016: homicídios por arma de fogo no Brasil. São Paulo: Instituto Sangari, Ministério da Justiça.

Zaluar, A. (1999). Um debate disperso violência e crime no Brasil da redemocratização. São Paulo em Perspectiva, v. 13, n.3, Fundação SEADE, 1999.

Zaluar, A. (2004). Integração perversa: pobreza e tráfico de drogas. Rio de Janeiro: FGV.

Zaluar, A.(2007). Democratização inacabada: fracasso da segurança pública. Estudos Avançados, vol.21 n.61 São Paulo, sept./dec. 2007, p.31-49.

Zaluar, A. (2010). Do dinheiro e dos homens no tráfico de drogas. In: Westphal, M. F., \& Bydlowski, C. R. (Eds.). Violência e juventude. São Paulo: Hucitec. 
Apêndice 1 - Dados estatísticos

Tabela 1 - Ocorrência de delitos e indicadores de vulnerabilidade social, bairros de Belém, média 2013-2015

\begin{tabular}{|c|c|c|c|c|c|c|}
\hline $\mathrm{N}^{0}$ & Bairro & $\begin{array}{c}\text { Hom } \\
100\end{array}$ & $\begin{array}{c}\text { Ate } \\
\text { MeioSM }\end{array}$ & Traf100 & $\begin{array}{c}\text { PopN } \\
\text { Branca }\end{array}$ & $\begin{array}{c}\text { Dom } \\
\text { Monop }\end{array}$ \\
\hline 1 & Agulha & 87,3 & 42,7 & 154,8 & 57,1 & 56,2 \\
\hline 2 & Barreiro & 77,0 & 53,9 & 141,6 & 60,5 & 65,3 \\
\hline 3 & Batista Campos & 12,9 & 9,1 & 16,5 & 41,7 & 53,4 \\
\hline 4 & Bengui & 138,3 & 47,4 & 122,3 & 57,5 & 60,0 \\
\hline 5 & Cabanagem & 169,8 & 53,2 & 164,1 & 59,7 & 59,5 \\
\hline 6 & Campina de Icoaraci & 38,6 & 38,8 & 85,8 & 57,9 & 54,5 \\
\hline 7 & Canudos & 55,6 & 21,6 & 29,1 & 56,6 & 59,6 \\
\hline 8 & Castanheira & 39,6 & 25,8 & 45,7 & 56,9 & 57,4 \\
\hline 9 & Cidade Velha & 35,4 & 13,7 & 70,7 & 49,4 & 60,3 \\
\hline 10 & Condor & 53,3 & 39,8 & 43,5 & 59,4 & 60,7 \\
\hline 11 & Coqueiro & 20,7 & 28,5 & 39,8 & 55,1 & 53,9 \\
\hline 12 & Cremacão & 51,4 & 23,4 & 51,4 & 54,6 & 50,1 \\
\hline 13 & Cruzeiro & 85,1 & 34,3 & 157,2 & 57,3 & 63,1 \\
\hline 14 & Curió-Utinga & 47,3 & 30,3 & 90,0 & 57,2 & 57,7 \\
\hline 15 & Fátima & 35,4 & 29,1 & 115,2 & 58,5 & 65,2 \\
\hline 16 & Guamá & 71,1 & 42,1 & 49,3 & 58,6 & 58,6 \\
\hline 17 & Jurunas & 65,2 & 36,0 & 62,2 & 57,5 & 61,8 \\
\hline 18 & Mangueirão & 34,1 & 31,6 & 29,8 & 56,8 & 60,3 \\
\hline 19 & Maracacuera & 95,1 & 53,4 & 208,1 & 55,4 & 58,8 \\
\hline 20 & Maracangalha & 37,9 & 35,3 & 16,4 & 58,9 & 54,4 \\
\hline 21 & Marambaia & 45,9 & 26,3 & 74,4 & 56,1 & 58,2 \\
\hline 22 & Marco & 38,6 & 18,0 & 37,5 & 53,3 & 55,8 \\
\hline 23 & Nazaré & 13,5 & 4,7 & 10,1 & 39,0 & 48,6 \\
\hline 24 & Parque Guajará & 42,1 & 52,9 & 46,8 & 55,6 & 51,7 \\
\hline 25 & Parque Verde & 65,5 & 37,1 & 77,4 & 55,7 & 51,7 \\
\hline 26 & Pedreira & 39,7 & 23,0 & 70,9 & 57,5 & 54,2 \\
\hline 27 & Ponta Grossa & 34,2 & 30,6 & 102,7 & 57,9 & 57,8 \\
\hline 28 & Pratinha & 89,6 & 51,2 & 91,4 & 57,0 & 59,8 \\
\hline 29 & Sacramenta & 96,7 & 34,1 & 101,0 & 59,5 & 57,8 \\
\hline 30 & Sao Brás & 33,4 & 9,1 & 61,6 & 46,2 & 66,4 \\
\hline 31 & Souza & 5,6 & 12,2 & 8,3 & 51,3 & 48,0 \\
\hline 32 & Tapanã & 82,1 & 45,6 & 127,3 & 56,1 & 52,8 \\
\hline 33 & Telégrafo & 63,2 & 35,2 & 91,3 & 59,7 & 56,4 \\
\hline 34 & Tenoné & 61,9 & 47,1 & 88,3 & 57,2 & 63,5 \\
\hline 35 & Terra Firme & 41,5 & 46,3 & 150,0 & 55,8 & 55,8 \\
\hline 36 & Umarizal & 11,7 & 12,1 & 16,4 & 48,4 & 49,4 \\
\hline
\end{tabular}

Fonte: IBGE (2010) e SEGUP.

Editor: Rodrigo José Firmino

Submissão: Jul. 02, 2018

Aprovação: Jun. 10, 2019 